\title{
BLICKDIAGNOSE
}

Diabetiker mit geschwollenem Knie

\section{Keine Schmerzen, großer Schaden}

— Ein 38-jähriger Patient mit einem langjährig unzureichend kontrollierten Typ-2-Diabetes stellte sich aufgrund einer spontan bemerkten zunehmenden Instabilität des linken Knies vor, nachdem einige Monate zuvor infolge einer Osteomyelitis eine linksseitige Vorfußamputation erfolgt war.

Klinisch zeigte sich bei der Aufnahme eine leicht gerötete, aber schmerzlose Schwellung des linken Knies (obere Abb.). Radiologisch fand sich eine komplette knöcherne Destruktion der proximalen Tibia und Fibula (untere Abb.). Anhalte für eine aktuelle Osteomyelitis ergaben sich bei der weiteren Diagnostik nicht.

Aufgrund der Anamnese, des typischen klinischen Bildes sowie der fehlenden Anhalte für eine anderweitige Ursache wurde die Diagnose einer diabetisch-neuropathischen Osteoarthropathie des Knies (sogenanntes Charcot-Knie) gestellt. Hierbei handelt es sich um eine seltene, aber sehr ernste Spätkomplikation des Diabetes mellitus, die üblicherweise im Rahmen einer erheblichen, neuropathisch bedingten Sensibilitätsstörung auftreten kann. Typischerweise manifestiert sich dies im Fußbereich (sogenannter Charcot-Fuß). Wie dieser Fall zeigt, können jedoch prinzipiell alle statisch belasteten Gelenke davon betroffen sein.

Zur Gelenkstabilisierung erfolgte eine Arthrodese des Knies. Der Patient konnte anschließend wieder erfolgreich mobilisiert und in sein häusliches Umfeld entlassen werden.

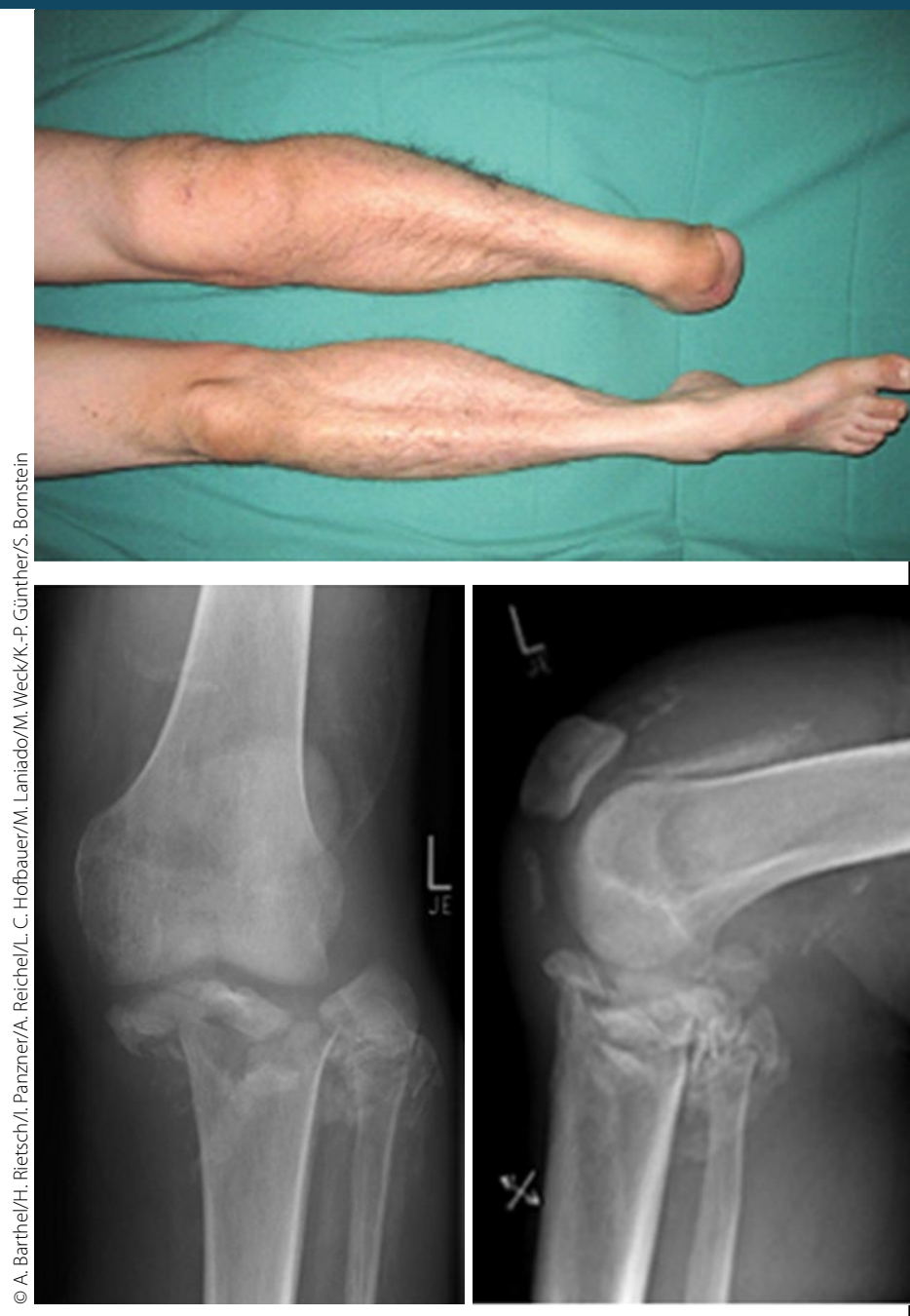

Keywords: diabetes mellitus, neuropathy, Charcot arthropathy

- PD Dr. Andreas Barthel ${ }^{(1,4)}$, Dr. Hannes Rietzsch ${ }^{(1)}$, Dr. Ines Panzner ${ }^{(2)}$, Dr. Andreas Reichel ${ }^{(1)}$, Prof. Dr. Lorenz C. Hofbauer ${ }^{(1)}$, Prof. Dr. Michael Laniado $^{(3)}$, PD Dr. Matthias Weck ${ }^{(1)}$, Prof. Dr. Klaus-Peter Günther ${ }^{(2)}$, Prof. Dr. Stefan R. Bornstein ${ }^{(1)}$

(1) Medizinische Klinik und Poliklinik III, ${ }^{(2)}$ Klinik und Poliklinik für Orthopädie, ${ }^{(3)}$ Institut und Poliklinik für Radiologische Diagnostik, Universitätsklinikum Carl Gustav Carus, D-01307 Dresden, ${ }^{(4)}$ Endokrinologikum Ruhr, D-44866 Bochum

\section{Weitere Infos auf springermedizin.de}

Weitere Blickdiagnosen finden Sie im Internet unter: - http://www.springermedizin.de/blickdiagnose 